\title{
Spatio-temporal patterns of drought evolution over the Beijing-Tianjin-Hebei region, China
}

\author{
ZHANG Jie ${ }^{1}$, ${ }^{*}$ UUN Fubao ${ }^{1}$, LIU Wenbin ${ }^{1}$, LIU Jiahong ${ }^{2}$, WANG Hong ${ }^{1}$
}

1. Key Laboratory of Water Cycle and Related Land Surface Processes, Institute of Geographic Science and Natural Resources Research, CAS, Beijing 100101, China;

2. Key Laboratory of Simulation and Regulation of Water Cycle in River Basin, China Institute of Water Resources and Hydropower Research, Beijing 100038, China

\begin{abstract}
Spatio-temporal patterns of drought from 1961 to 2013 over the Beijing-Tianjin-Hebei (BTH) region of China were analyzed using the Palmer Drought Severity index $(P D S I)$ based on 21 meteorological stations. Overall, changes in the mean-state of drought detected in recent decades were due to decreases in precipitation and potential evapotranspiration. The Empirical Orthogonal Functions (EOF) method was used to decompose drought into spatio-temporal patterns, and the first two EOF modes were analyzed. According to the first leading EOF mode (48.5\%), the temporal variability (Principal Components, PC1) was highly positively correlated with annual series of $P D S I(r=+0.99)$. The variance decomposition method was further applied to explain the inter-decadal temporal and spatial variations of drought relative to the total variation. We find that $90 \%$ of total variance was explained by time variance, and both total and time variance dramatically decreased from 1982 to 2013. The total variance was consistent with extreme climate events at the inter-decadal scale $(r=0.71, p<0.01)$. Comparing the influence of climate change on the annual drought in two different long-term periods characterized by dramatic global warming (P1: 1961-1989 and P2: 1990-2013), we find that temperature sensitivity in the P2 was three times more than that in the P1.
\end{abstract}

Keywords: PDSI; spatial and temporal patterns; sensitivity analysis; global warming

\section{Introduction}

Drought, one of the most widespread natural hazards, is caused by a long-term shortage of precipitation and increase in evaporation (Sheffield et al., 2012; AghaKouchak et al., 2014). Positive temperature, wind speed, radiation, and low relative humidity anomalies play a significant role generating extreme drought events (Diffenbaugh et al., 2015; Wang et al., 2015; Huang et al., 2017). In recent years, a higher frequency of extreme drought events has been

Received: 2018-05-12 Accepted: 2018-11-23

Foundation: National Key Research and Development Program of China, No.2016YFC0401401, No.2016YFA0602402; Key Program of the Chinese Academy of Sciences, No.ZDRW-ZS-2017-3-1; The Chinese Academy of Sciences (CAS) Pioneer Hundred Talents Program; National Natural Science Foundation of China, No.41601035

Author: Zhang Jie, PhD, specialized in climate change and hydrological process. E-mail: zhangjie@igsnrr.ac.cn

"Corresponding author: Sun Fubao, Professor, E-mail: sunfb@igsnrr.ac.cn 
observed concurrent with dramatic global warming at global and regional scales (Dai, 2013; Zhang et al., 2013; Griffin and Anchukaitis, 2014; Schwalm et al., 2017). The long-term shortage of water resources can lead to drought disasters (Wang et al., 2015; Huang et al., 2017). In particular, China has suffered more frequent drought events in the early 21 st century (Yu et al., 2014) and previous studies have highlighted the severe droughts in North China since 1960, with a higher frequency after the 1990s (Qin et al., 2015; Wang and He, 2015; Zhang et al., 2017). With a soaring economy and population growth, the risk and influence of drought disasters have increased significantly in North China (Cai et al., 2015). For example, the Haihe River Basin has been subject to increasing drying-out events due to high-intensity water resource utilization in recent decades. Even more serious, the groundwater table sharply declined from 3-4 m depth in the 1950s to greater than $30 \mathrm{~m}$ depth in the 1990s (Liu and Xia, 2004). Thus, extreme drought events have received more attention in most regions over China, including North China (Wu et al., 2018).

Despite trends in global warming and climate change, previous studies have noted that drought trends have shown negligible increases worldwide or in China (Sheffield et al., 2012; Zhang et al., 2016). The impact of global warming on drought has been almost completely offset by declining evaporation (Chen et al., 2005; Zhang et al., 2016) due to decreasing wind speeds ('global stilling', Young et al., 2011) and radiation reductions ('global dimming', Wild et al., 2005). As a result, the variance in drought is increasing with global warming with little change in tendency (Rajah et al., 2014).

Exploring the spatio-temporal patterns of drought can help us better understand the impact of climate change and human activity on drought (Sun et al., 2012; Greve et al., 2014). To evaluate drought characteristics, a series of indices, including the widely used Standardized Precipitation Index (SPI) (McKee et al., 1993), Standardized Precipitation Evapotranspiration Index (SPEI), and Palmer Drought Severity Index (PDSI) (Palmer, 1965), have been proposed. These indices have proven useful in exploring the factors driving extreme drought events, i.e., based on monthly precipitation and potential evapotranspiration datasets, and quantifying drought characteristics, i.e., the severity, intensity, and duration of drought (Yang et al., 2017; Zhai et al., 2017). Among them, PDSI is most widely used because of the clear physical mechanism (Palmer, 1965; Zhang et al., 2016; Yang et al., 2017). More recently, a series of variance decomposition methods, combined with drought indices, were introduced to diagnose and separate the spatio-temporal patterns of drought (Santos et al., 2010).

Drought characteristics over the Beijing-Tianjin-Hebei region have been investigated using various drought indices. He et al. (2015) noted that, based on the comprehensive drought index, the risk of severe and extreme drought events has increased in the early 21 st century. Using SPI, the most serious drought was identified as occurring from 2005 to 2007 (Qin et al., 2014). In terms of future drought, SPEI projections have been forecast based on outputs from regional climate models under 1.5 and $2.0^{\circ} \mathrm{C}$ global warming scenarios, and the frequency of drought under the $2.0^{\circ} \mathrm{C}$ warming scenario will increase due to reduced precipitation and increases in evaporation demand (Sun et al., 2017). However, research focusing on drought characteristics still lack detailed spatio-temporal characteristics on inter-decadal scales. To address this limitation, this study focuses on the spatio-temporal pattern of 
drought evolution and sensitivity analysis over the Beijing-Tianjin-Hebei region for 1961-2013.

\section{Study area, data, and methods}

\subsection{Study area and data}

In this study, we focus on the Beijing-Tianjin-Hebei region (hereafter the BTH region), generally located in North China (Figure 1). The BTH region is approximately $185,000 \mathrm{~km}^{2}$ in area and is both one of the major grain producing areas and largest urban agglomerations in China. To better understand the spatio-temporal pattern of drought, we used a daily meteorological dataset to calculate the PDSI for 1961-2013; the dataset includes precipitation (denoted $P$ ), air temperature (mean, maximum, minimum) (denoted $T$ ), wind speed (denoted $W s$ ), sunshine duration (denoted $S d$ ), and relative humidity (denoted $R h$ ). Data were obtained from 29 stations and subject to quality-control measures before release from the Natioal Climate Center of the China Meteorological Administration to the scientific community (http:// www. nmic. gov. $\mathrm{cn} /$ ). In this study, we also chose data for temporal consistency using available data length; for inclusion, missing data had to be less than $5 \%$ and the longest continuous missing days less than 10 days. With these quality control measures, 21 out of the 29 meteorological stations had enough data with continuous measre-

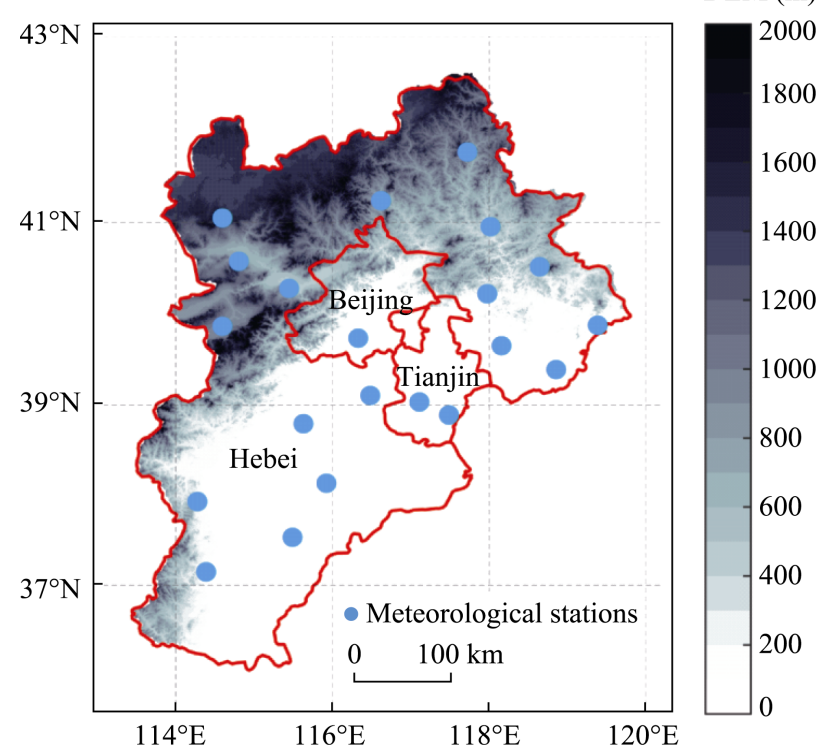

Figure 1 Location of the study area and selected sites in the $B T H$ region ments.

\subsection{Methods}

\subsubsection{Palmer Drought Severity Index (PDSI)}

We selected $P D S I$ as a quantifiable evaluation indicator, which considers both precipitation and evaporation. PDSI is a simple-double layer water balance model originally designed by Palmer (1965), which indicates the balance between water supply and atmospheric evaporative demand on monthly time scales.

The PDSI is calculated using the difference between the observed monthly precipitation and most-optimum "precipitation", which are estimated based on monthly Climatically Appropriate For Existing Conditions (CAFEC). To estimate the most-optimum "precipitation" under $C A F E C$, we selected the $F A O$ (Food and Agricultural Organization) Penman-Monteith reference evaporation, as recommended by previous studies instead of the original Thornthwaite approach, which only considers mean near-surface temperature (Thornthwaite, 
1948). The drought classifications using PDSI are shown in Table 1.

Table 1 Drought classifications using PDSI

\begin{tabular}{cccc}
\hline Drought class & $P D S I$ values & Drought class & $P D S I$ values \\
\hline Extreme wet & $P D S I>4$ & Extreme drought & $P D S I<-4$ \\
Severe wet & $3<P D S I \leqslant 4$ & Severe drought & $-4<P D S I \leqslant-3$ \\
Moderate wet & $2<P D S I \leqslant 3$ & Moderate drought & $-3<P D S I \leqslant-2$ \\
Mild wet & $1<P D S I \leqslant 2$ & Mild drought & $-2<P D S I \leqslant-1$ \\
Normal & $-1<P D S I \leqslant 1$ & & \\
\hline
\end{tabular}

We used a standard algorithm to estimate potential evapotranspiration (PET) as recommended by the FAO (Allen et al., 1998); the FAO-Penmen-Monteith (PET pm) approach is given by:

$$
\text { PET_pm }=\frac{0.408 \Delta\left(R_{n}-G\right)+\gamma \frac{900}{T+273} U_{2} \cdot e_{s}(1-R h / 100)}{\Delta+\gamma\left(1+0.34 U_{2}\right)}
$$

where $R_{n}$ is net radiation, $\Delta$ is slope of the vapor pressure curve, $G$ is soil heat flux, $U_{2}$ is the wind speed $(W s)$ at 2-m height, $\gamma$ is the psychometric constant, $e_{S}$ is saturation vapor pressure at a given air temperature, $R h$ is the relative humidity, and $e_{s}(1-R h / 100)$ is the vapor pressure deficit.

\subsubsection{Empirical Orthogonal Function $(E O F)$}

For a large or complex dataset, the Empirical Orthogonal Function $(E O F)$ can reduce the dimensionality; therefore, it is widely used to extract useful information. Here, the EOF method (Perry and Niemann, 2008) was applied to analyze the spatio-temporal pattern of drought over the BTH region. In this study, the annual and seasonal series PDSI, containing a 52-year sample length from 1962 to 2013 and 1961 as a warm-up year, was considered as a $21 \times 52$ matrix. Using empirical orthogonal decomposition, a set of orthogonal functions to represent a time series of drought was obtained as follows:

$$
Z(x, y, t)=\sum_{i=1}^{n} P C(t) \times E O F(x, y)
$$

where $Z(x, y, t)$ is the original time series dataset as a function of time (principal components, $P C s$ ) and space (EOF modes, EOFs) and $n$ is sample size of space (here, $\mathrm{n}=21$ ). To eliminate the influence of multicollinearity between time and space, the orthogonal transformation was used to investigate the spatio-temporal pattern of droughts.

\subsubsection{Decomposition of time-space variance}

Changes in precipitation and evapotranspiration impact the intensity and severity of drought. In general, drought indices, such as PDSI, perform well as a quantitative drought assessment. However, it is difficult to separate the space and time components of variances because of their interaction within the whole system. Here, we used a variance decomposition method (Sun et al., 2010; Sun et al., 2012) to quantify the separate effects of spatio-temporal drought variability relative to total variability. A 10 -year moving window was used to indicate the inter-decadal change. Hence, a set of decade PDSI series (1962-1971, 1963- 
$1972, \ldots, 2004-2013)$ including the 21 stations over the BTH region was analyzed.

\subsubsection{Sensitivity analysis using multiple linear regression}

Multiple linear regression was used to quantify the contribution of meteorological variables in drought (Karnieli et al., 2010; Li et al., 2014). In this sensitivity analysis, relative humidity $(R h)$ was eliminated because of multicollinearity between $P$ and $R h$ (Hardwick et al., 2010). To compare all independent variables, we first normalized the annual series of each variable as a dimensionless series with large sample size $(\mu=0 ; \sigma=1)$ :

$$
X_{i}=\frac{\left(x_{i}-\bar{x}\right)}{\sigma(x)}
$$

where $x$ is original annual series, i.e., $P, T, W s$, and $S d$, and $X$ is the dimensionless series. In this study, the trend of the time series was quantitatively evaluated using Sen's slope in the non-parametric Mann-Kendall test (Mann, 1945; Kendall, 1975)

\section{Results}

\subsection{Changes in recent decades of drought}

Within the PDSI, $P$ and PET are two of the most important components, so were analyzed first over recent decadal periods. As shown in Figure 2a, 1964 had over $800 \mathrm{~mm}$ of annual precipitation, which sharply reduced to less than $400 \mathrm{~mm}$ in the early $2000 \mathrm{~s}$. Over the BTH, annual precipitation shows an insignificant decreasing trend of about $8 \mathrm{~mm} \cdot 10 \mathrm{a}^{-1}(P=0.12)$ and the PET (Figure $2 \mathrm{~b}$ ) shows a significant decreasing trend $\left(-10 \mathrm{~mm} \cdot 10 \mathrm{a}^{-1}, P<0.01\right)$.
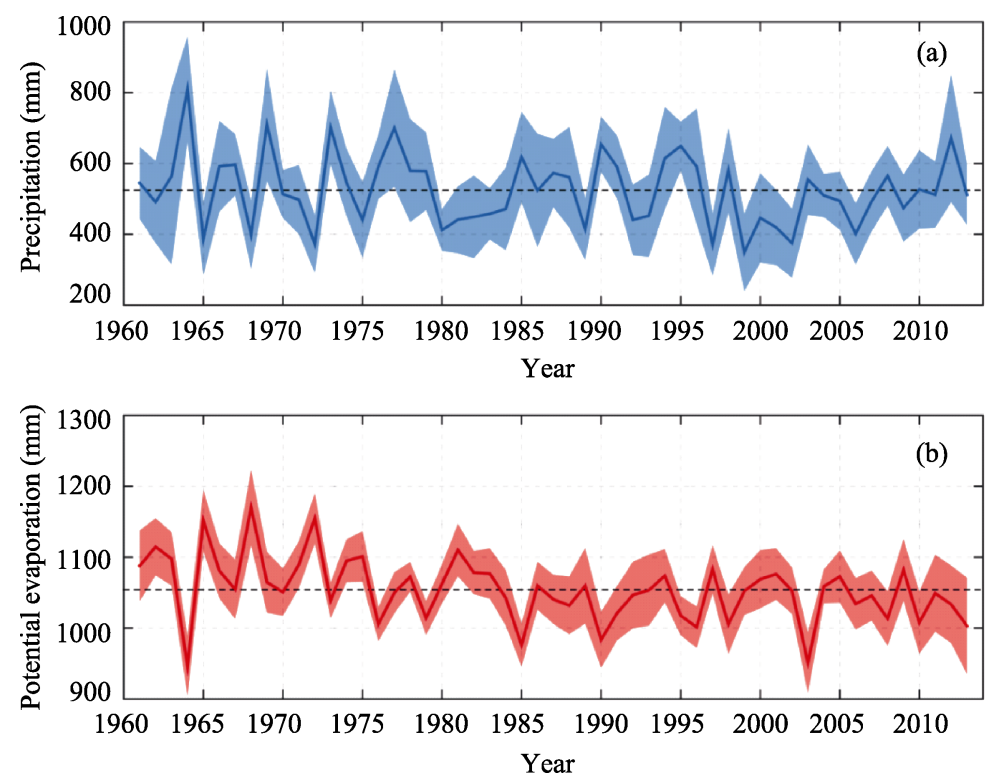

Figure 2 Changes in $P$ and PET over the BTH region from 1961-2013 (the shaded range in both of subplots are estimated from $\sqrt{\sigma} / n$, where $n$ is 21 )

To better understand the characteristics of drought, we prepared a long-term series of annual PDSI over the BTH region. We found an insignificant decrease in drought over recent 
decades $\left(P D S I_{\text {Trend }}=-0.04, P>0.05\right)$, as shown in Figure 3 a. To investigate spatial differences in drought, we evaluated the trends in $P$ and PET (Figures 3b-3c). Clear spatial differences were found in both $P$ and PET analyses. Precipitation has drastically decreased in the eastern BTH region (Figure 3b) and a dramatic decreasing trend (about $-25 \mathrm{~mm} \cdot 10 \mathrm{a}^{-1}$ ) was quantified in the southern BTH region. Incorporating both $P$ and $P E T$, a different $P D S I$ spatial pattern was found, as shown in Figure 3d; a dramatic decrease in PDSI (drier, from $-0.2 \cdot 10 \mathrm{a}^{-1}$ to $-0.27 \cdot 10 \mathrm{a}^{-1}$ ) was detected in the northern and southern BTH region. The drier trend in the southern BTH region accompanied a dramatic decrease in precipitation, whereas the drier trend in the northern BTH region accompanied a decrease in precipitation and slight increase in PET. A significant increase in PDSI was found in the northwestern BTH region (wetter, from $0.16 \cdot 10 \mathrm{a}^{-1}$ to $0.21 \cdot 10 \mathrm{a}^{-1}$ ) due to a significant decrease in PET (Figure 3c).

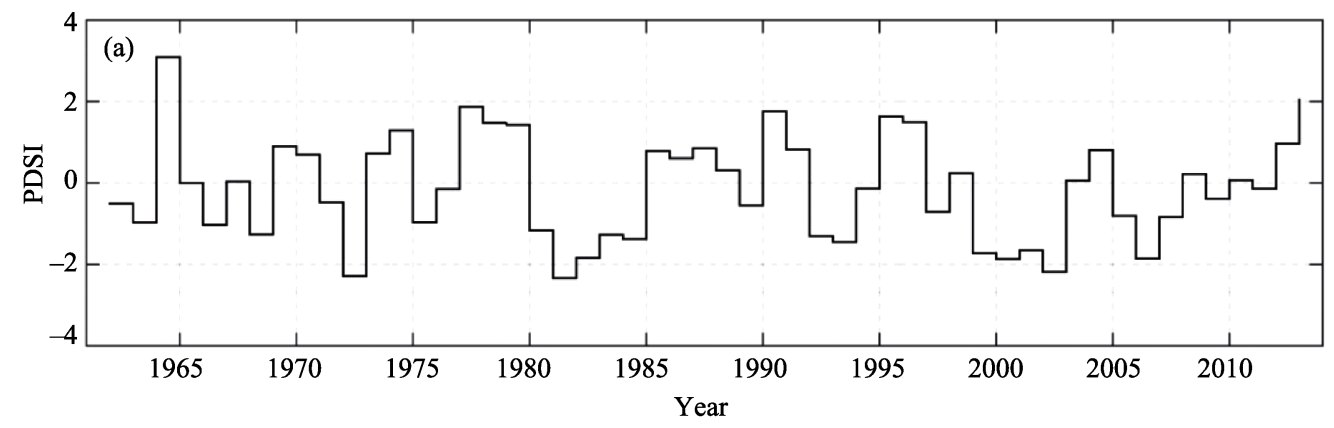

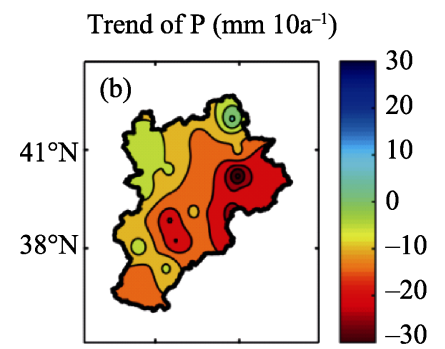

$115^{\circ} \mathrm{E} 118^{\circ} \mathrm{E}$

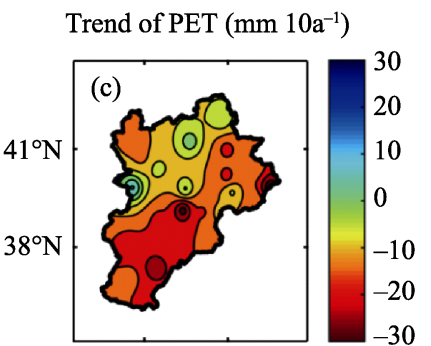

$115^{\circ} \mathrm{E} 118^{\circ} \mathrm{E}$
Trend of PDSI $\left(10 \mathrm{a}^{-1}\right)$

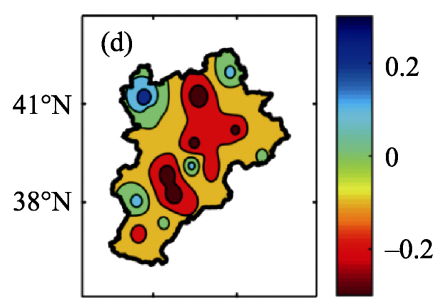

$115^{\circ} \mathrm{E} 118^{\circ} \mathrm{E}$

Figure 3 Drought analyses for 1960-2013, time series of annual PDSI (a) and spatial patterns for $P$ trends (b), PET trends (c), and PDSI trends (d)

\subsection{Agreement between inter-annual and seasonal scales}

Previous studies have indicated that drought analysis results can be quite different on inter-annual and seasonal scales (Wang et al., 2015). To ensure that results for inter-annual scales match the seasonal scale, we calculated the four seasonal PDSIs using the same 21 stations: $P D S I_{\text {spring }}$ from March to May; $P D S I_{\text {summer }}$ from June to August; $P D S I_{\text {autumn }}$ from September to November, and $P D S I_{\text {winter }}$ from November to February of the following next year. The results comparing the annual and seasonal trends using Pearson Correlation Coefficient $(r)$ are shown in Figure 4. With respect to agreement with the annual trends, the seasonal trends rank from high to low as $P D S I_{\text {winter }}(r=0.95)>P D S I_{\text {spring }}(r=0.93)>P D S I_{\text {autumn }}$ $(r=0.91)>P D S I_{\text {summer }}(r=0.85)$. In addition, the relationships between inter-annual and seasonal series drought fluctuations were explored for each station (Figure 5). All 21 stations 

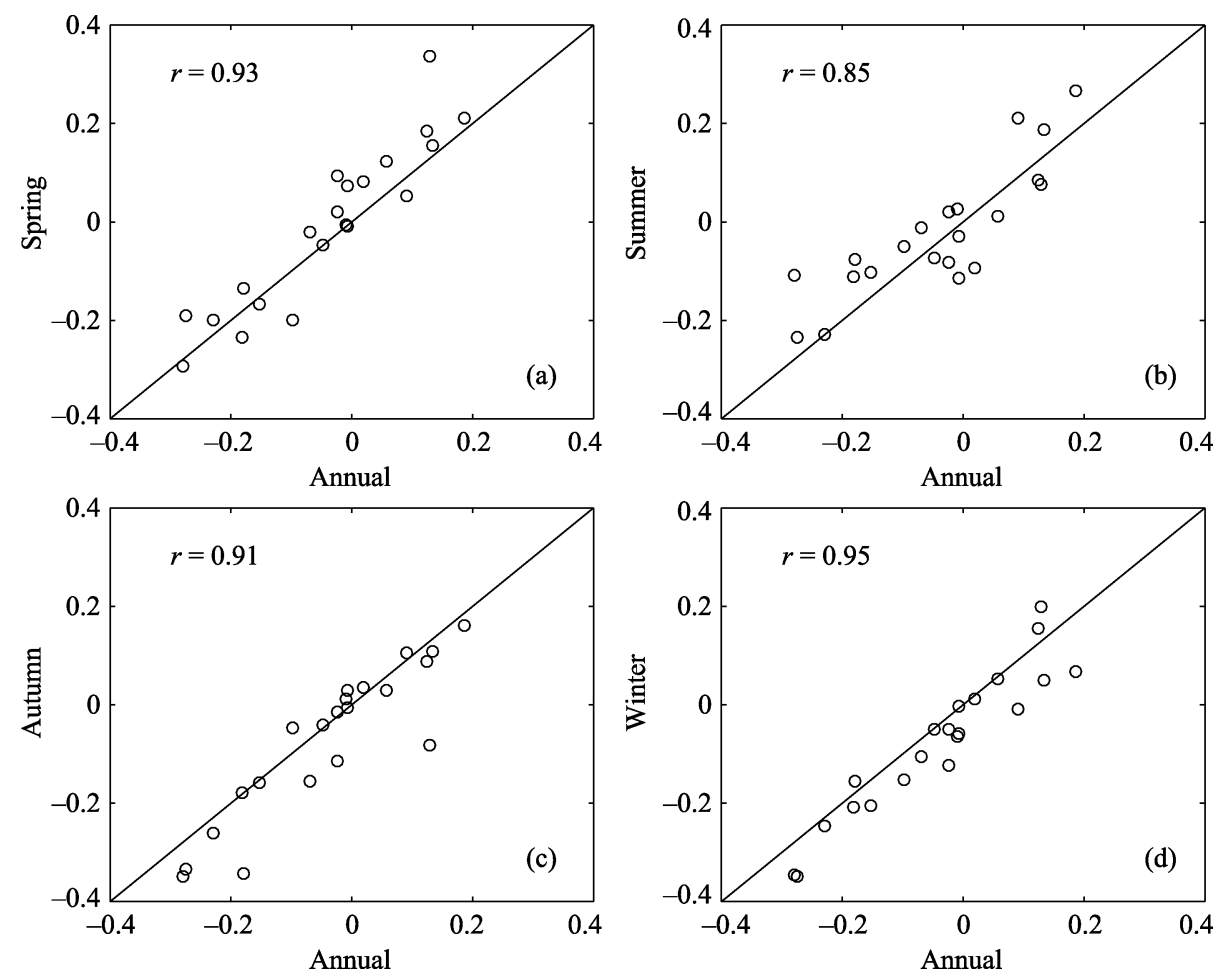

Figure 4 Correlation between PDSI trends on annual and seasonal scales (from spring to winter)

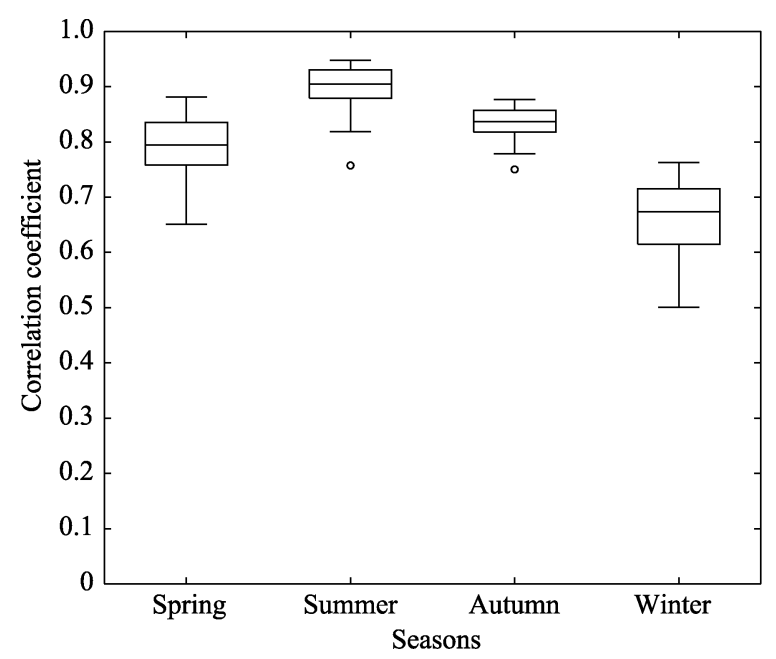

Figure 5 Boxplot of correlation coefficients between seasonal and annual PDSI series

showed a high agreement between fluctuations on seasonal and inter-annual scales $(r>0.5$, $\bar{r}=0.78)$. The highest agreement was found for summer $(0.75<r<0.93, \bar{r}=0.90)$ and the lowest for winter $(0.5<r<0.75, \bar{r}=0.66)$.

\subsection{Spatio-temporal patterns of drought using the $E O F$}

The EOF analysis was performed on the annual and seasonal drought series to define significant drought patterns. According to the variance contribution for annual PDSI, the first two leading EOFs were selected in this study. The corresponding principal components can 
be used to explain the main characteristics of the spatio-temporal variation of drought (Table 2). The first two EOF modes and the corresponding principal components (PCs) explain approximately $48.5 \%$ and $10.8 \%$ of the total variances of drought.

Table 2 Variance contribution (\%) of annual PDSI from the first six leading EOFs modes

\begin{tabular}{ccccccc}
\hline & EOF1 & EOF2 & EOF3 & EOF4 & EOF5 & EOF6 \\
\hline Contribution (\%) & 48.2 & 10.8 & 9.8 & 4.9 & 4.5 & 4.3 \\
Cumulation (\%) & 48.2 & 59.0 & 68.8 & 73.7 & 78.2 & 82.5 \\
\hline
\end{tabular}

The first leading $E O F$ mode $(E O F 1)$ primarily reflects the spatial pattern in the BTH region. Because of the overall positive $E O F 1$ value, distinct negative values in the time series of PC1, e.g., 1981-1986 and 1999-2003, indicate long-term dry periods (Figures 6a and 6b). These two long-term drought periods are easily confirmed using the annual PDSI series (Figure 3a); the subsequent drought alleviation after 2006 is indicated in both the PDSI and EOF1 (Figures 3a and 6b).
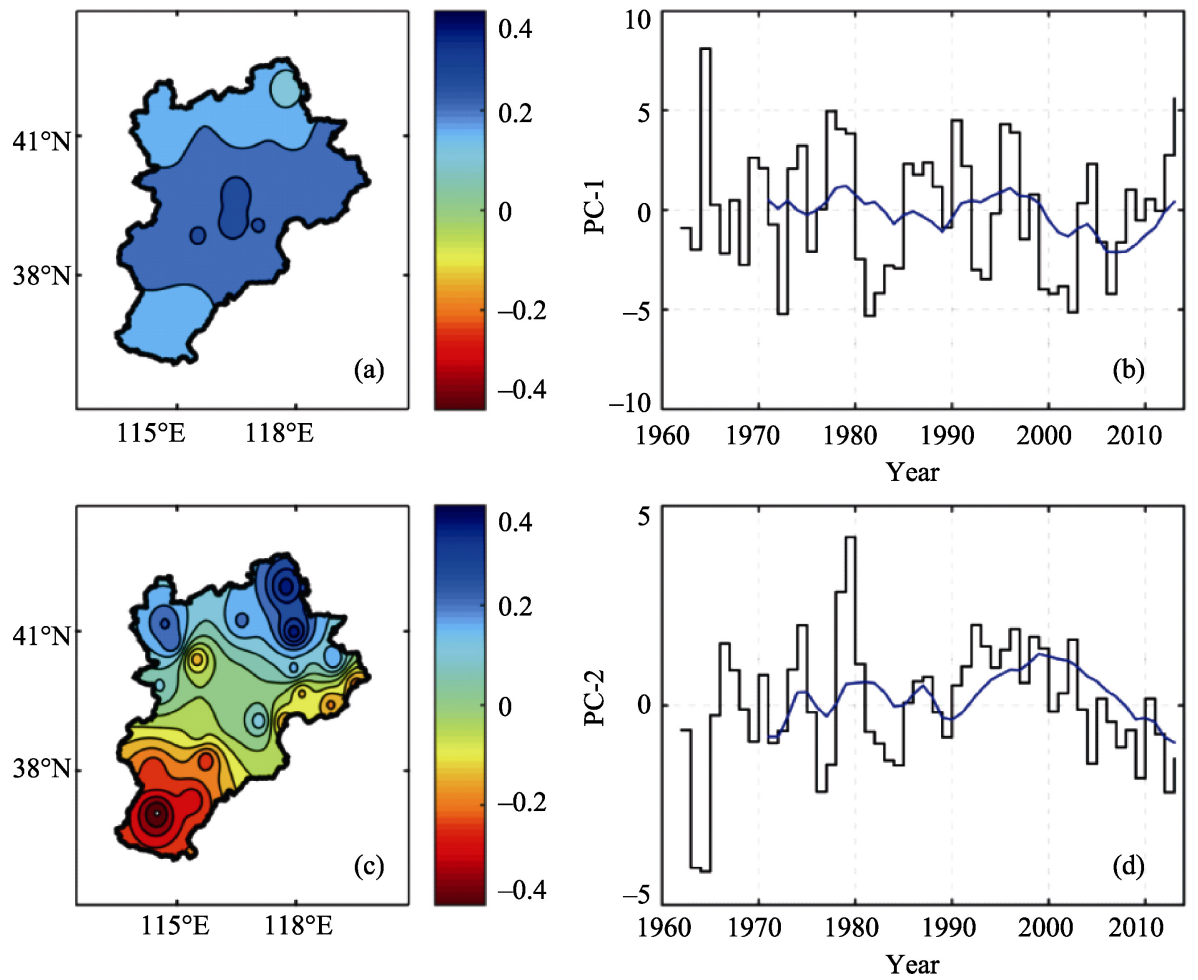

Figure 6 Spatial (left) and temporal (right) patterns of the first two leading EOFs for annual PDSI. The blue line indicates the 10-year moving average of PCs in (b) and (d).

The second leading EOF (EOF2) mainly reflects positive and negative differences corresponding to the northern and southern regions (Figure $8 \mathrm{c}$ ), which result from the influence of atmospheric circulation and topography (Wang et al., 2015). According to the anti-phase distribution of EOF2, the positive (negative) values of $P C 2$ are wet (dry) years in sub-regions with positive EOF2 values. For example, the positive EOF2 in the northern BTH region is associated with the wet period from 1979 to 1980 concurrent with dry years found in the southern BTH region. An opposite spatial pattern was detected for 1962-1963, indicating the dry (wet) years in the northern (southern) in the same periods, and a highly 
negative spatial correlation with average annual PET $(r=-0.59)$.

We further compared the spatio-temporal patterns between annual and seasonal scales and found that the spatial distribution of seasonal $E O F$ had the same pattern as the annual EOF. For the first leading $E O F$, the correlation coefficients between annual $E O F$ and seasonal $E O F$ are all above +0.93 at station scales (Figures $7 \mathrm{a}-\mathrm{d}$ ). The $P C$ correlation coefficients between seasonal (summer) and annual are over $+0.7\left(r_{P C s 1}=0.86\right.$ and $r_{P C s 2}=0.78$, Figure 8 ), which indicates that the spatio-temporal patterns at annual scales are similar to those of seasonal scales.
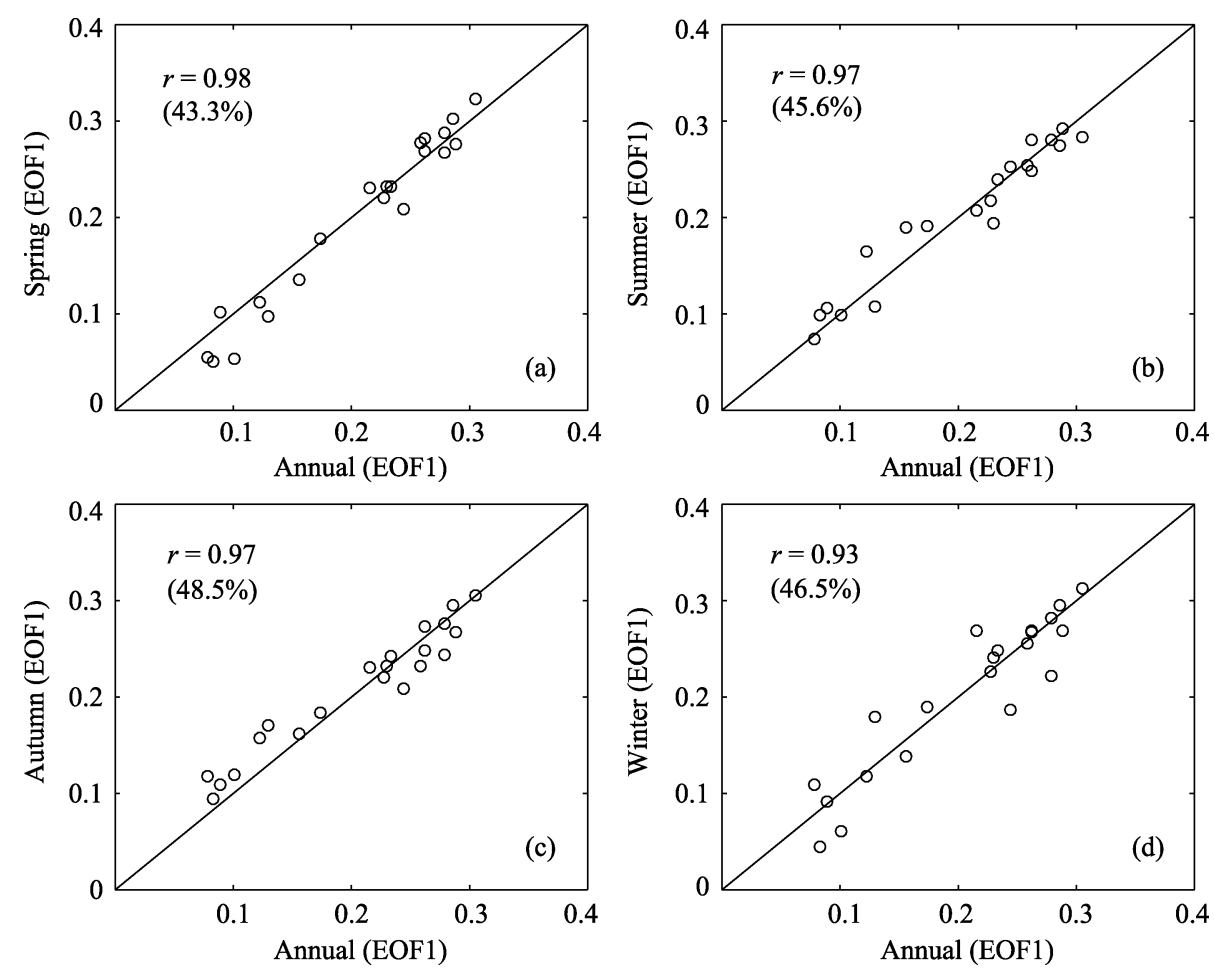

Figure 7 Correlation between annual and seasonal $E O F$ for $E O F 1$

\subsection{Partitioning the spatio-temporal variance of drought}

In this study, we used a decomposition method to separate total drought variance into time and space variance; we found that $90 \%$ of total variance can be explained by time variance. Overall, total variance in PDSI decreased between the 1960s (1962-1971) and 2010s (2004-2013), with a particularly dramatic decrease after the $1980 \mathrm{~s}\left(-0.52 \cdot 10 \mathrm{a}^{-1}\right.$, Figure $\left.9 \mathrm{a}\right)$. Time variance was in agreement with total variance, showing a decreasing trend after the $1980 \mathrm{~s}\left(-0.58 \cdot 10 \mathrm{a}^{-1}\right.$, Figure $\left.9 \mathrm{~b}\right)$. However, the increase in spatial variance showed decadal oscillations after the $1980 \mathrm{~s}\left(+0.06 \cdot 10 \mathrm{a}^{-1}\right.$, Figure 9c). Previous studies have noted that ex treme climate events are increasing despite a small change in the mean-state over recent decades (Rajah et al., 2014; Donat et al., 2016). Here, we count both drought and wetting (as a proxy for potential flood risk) events as extreme events $(P D S I<-2$ and $P D S I>+2)$ to determine whether total variance can explain changes in extreme events at decadal scales. The agreement between total variance and the timing of extreme events is shown in Figure 9d. Generally, the change in total variance (or time variance) has a 20 -year periodicity, which is consistent with the frequency of extreme events $(r=+0.71)$. 

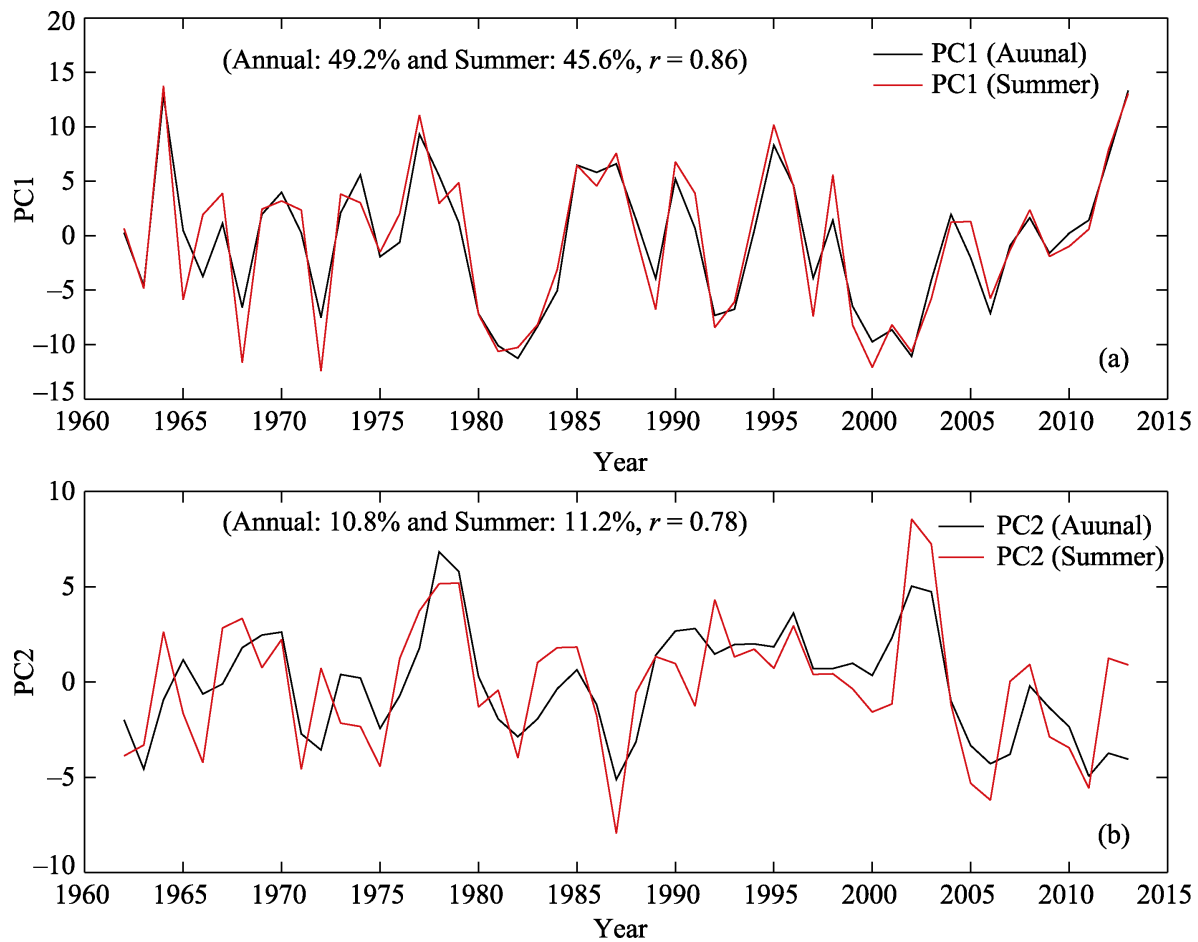

Figure 8 Correlation between annual $P C$ and summer $P C$ for $E O F 1$ (a) and $E O F 2$ (b)
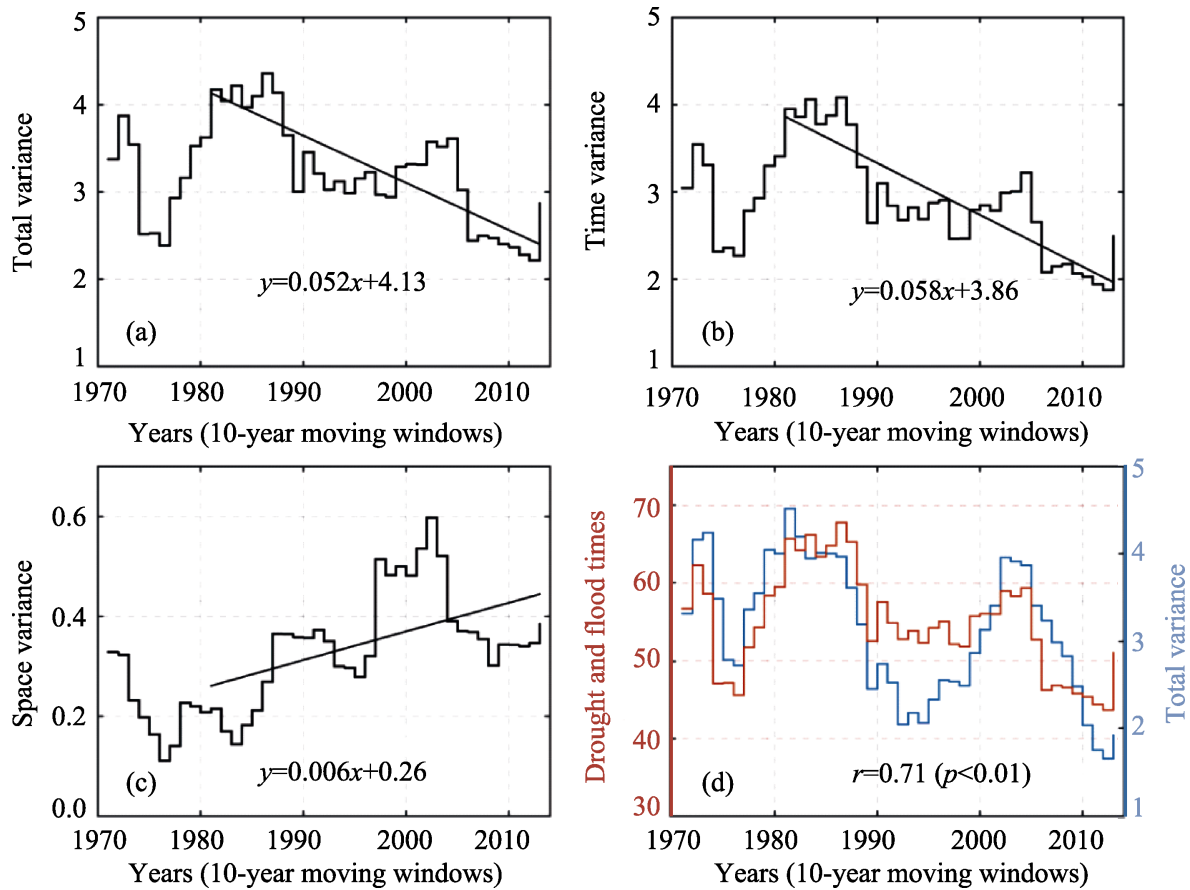

Figure 9 Variance decomposition for 10-year PDSI (10-year moving window) from 1982-2013. (a) Total variance, which decreases $\left(-0.052 \cdot \mathrm{a}^{-1}\right)$. (b) Time variance, which decreases $\left(-0.058 \cdot \mathrm{a}^{-1}\right)$. (c) Spatial variance, which increases $\left(0.006 \cdot \mathrm{a}^{-1}\right)$. (d) Comparison between total variance and the frequency of extreme events $(P D S I<-2$ and $P D S I>2)$. 


\subsection{Causes of drought fluctuations identified with multiple linear regression}

Previous studies have highlighted the impact of abnormally high temperatures and shortage of precipitation on increasing the risk of extreme drought events. Using anomalous changes in precipitation, temperature, wind speed, radiation, and relative humidity, fluctuations in meteorological drought can be identified. In the context of dramatic global warming in recent decades, extreme drought events have generally occurred concurrent with long-term precipitation deficiencies and abnormally high temperatures. However, a more quantitative approach can evaluate the contribution from different causes. The regression coefficient $(R C)$ obtained from the multiple linear regression method is an appropriate mechanism for identifying a variable as independent (Karnieli et al., 2010). Here, we prepared a long-term annual temperature series (from 1961 to 2013) over the BTH region (Figure 10). We found that the annual temperature slowly increased in Period one (P1), from 1961 to 1989, with a mean of annual temperature of $9.65^{\circ} \mathrm{C}$, followed by a dramatic increase after the early 1990 s and decadal warming hiatus after the early 2000s. Period two (P2), from 1990-2013, is thus characterized by a higher annual temperature $\left(\right.$ mean $\left.=10.65^{\circ} \mathrm{C}\right)$ and considered an intensification of global warming.

The influence of climate change on the annual drought in two different long-term periods (P1 and P2) was compared in this study. To confirm that the variables were independent, we selected $P, T, W s$, and $S d ; R h$ was excluded because of the high interaction effect between $R h$ and $P$.

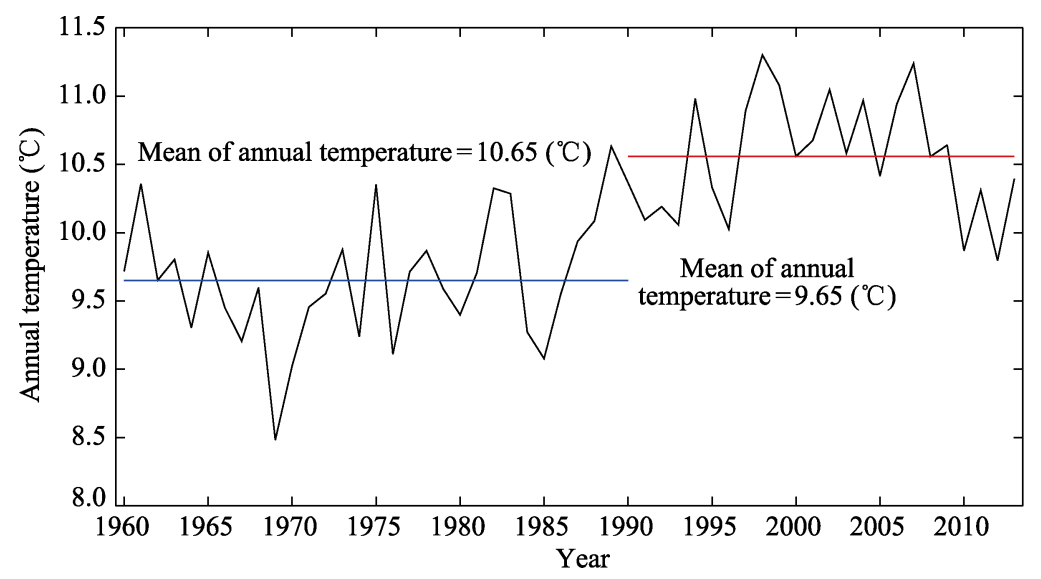

Figure 10 Mean annual temperature from 1961 to 2013 over the BTH region

The contribution from precipitation to drought has the highest positive regression coefficient, ranging from +0.7 to +1.8 in $\mathrm{P} 1$ and $\mathrm{P} 2$ (Figure 11a) and the medians are equivalent in the two different long-term periods $\left(R C_{P_{-} \mathrm{P} 1}=+1.2\right.$ and $\left.R C_{P_{-} \mathrm{P} 2}=+1.3\right)$, about $70 \%$ of the sum of the absolute value in the regression coefficients. The contribution from $T$ is relatively insensitive in P1 (median $R C_{T_{-} \mathrm{P} 1}=-0.14$ ), but more sensitive to drought during $\mathrm{P} 2$, with dramatic global warming (median $R C_{T_{-} \mathrm{P} 2}=-0.44$ ). Wind speed is also an important factor because it accelerates atmospheric evaporative demand. The contribution from wind speed in the two different periods is opposite to the contribution from temperature (median $R C_{W s_{-} \mathrm{P} 1}$ $=-0.40$, median $\left.R C_{W s_{-} \mathrm{P} 2}=-0.13\right)$. Comparing temperature and wind speed, drought is three 
times more sensitive to wind speed compared to that of temperature in P1, whereas the opposite result was found in $\mathrm{P} 2$. In contrast, changes in drought are relatively insensitive to radiation, with a slight negative regression coefficient during both P1 and P2 (Figures 11a and 11b).
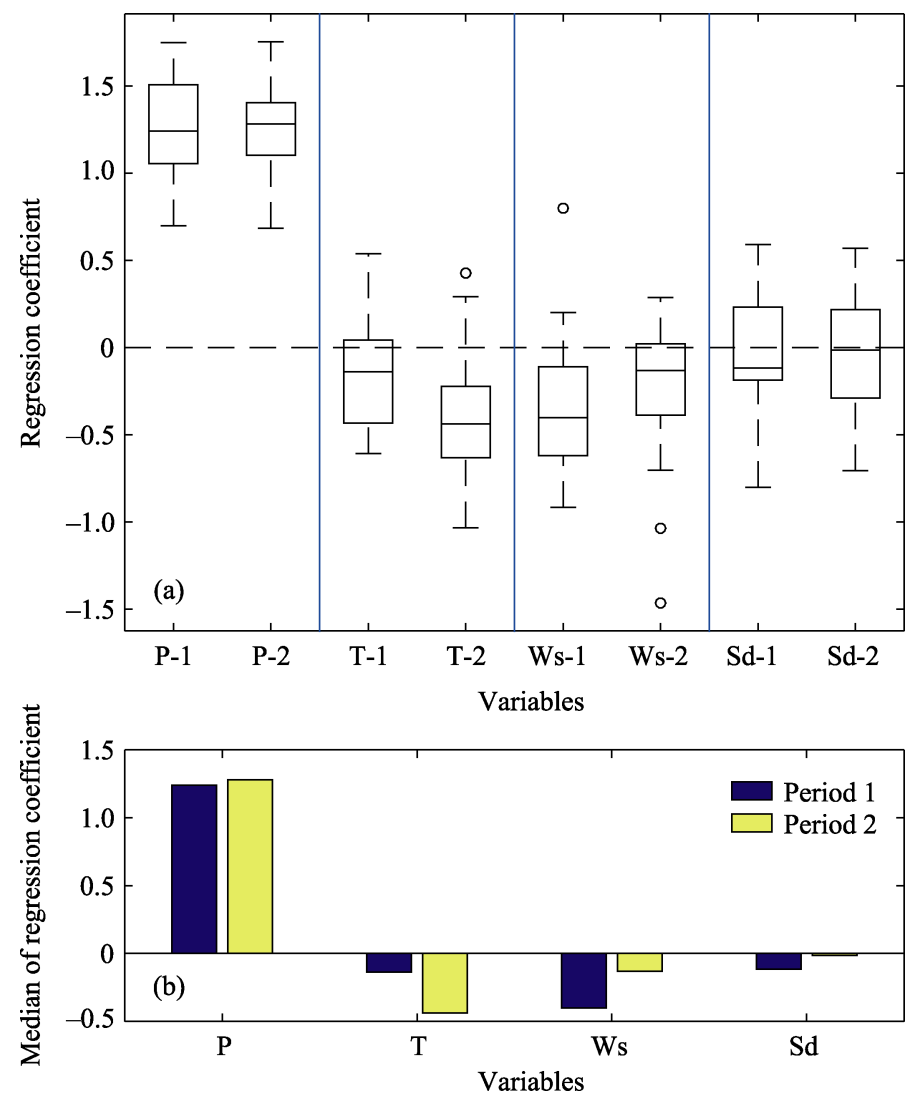

Figure 11 Drought sensitivity analysis using regression coefficients from multiple linear regression, (a) boxplot of regression coefficients and (b) regression coefficient median values

\section{Discussion and conclusions}

PDSI, one of the most widely used drought indices that considers both monthly precipitation and potential evapotranspiration, was selected to analyze the spatio-temporal evolution of drought patterns over the BTH region for 1961-2013. We separately analyzed annual trends in $P, P E T$, and PDSI and found decreasing trends in $P$ and $P E T$ in recent decades. The overall drought index, PDSI, showed a nonsignificant drying trend $\left(P D S I\right.$ trend $\left.=-0.05 \cdot 10 \mathrm{a}^{-1}, p>0.05\right)$ over the entire study area. The small trend represents a balance between the significant decreases in $P$ and $P E T$. Within the study area, large spatial differences were noted: a dramatic decrease in PDSI (drier, from $-0.2 \cdot 10 \mathrm{a}^{-1}$ to $-0.27 \cdot 10 \mathrm{a}^{-1}$ ) in two sub-regions and a dramatic increase in PDSI in the northwestern BTH region (wetter, from $0.16 \cdot 10 \mathrm{a}^{-1}$ to $0.21 \cdot 10 \mathrm{a}^{-1}$ ). On seasonal scales, $P D S I$ trends were in agreement with those on an annual scale.

The EOF was applied to explain the spatio-temporal variation patterns on annual and seasonal scales. The first two leading EOF modes of PDSI explained 59\% of the total vari- 
ability (first mode, $47.5 \%$ and second mode, $11.5 \%$ ). In the first EOF mode, there was a similar spatial pattern, wherein all regions showed a positive value, from +0.12 to +0.27 . The temporal variability of the first mode had a highly positive correlation with the annual PDSI series $(r=+0.99)$. For the second leading EOF mode, the spatial distribution showed positive values in the north and negative values in the south.

The variance decomposition method was applied to explain the inter-decadal spatio-temporal pattern of drought. We found $90 \%$ of total variance can be explained by time variance, and both total and time variance show a decreasing trend from 1982 to 2013. Furthermore, the total variance was consistent with extreme climate events $(r=0.71, p<0.01)$.

Finally, we used the multiple linear regression method to quantify drought sensitivity to several factors. In two periods, P1 (1962-1989) and P2 (1990-2013), 70\% fluctuations in drought were attributed to changes in precipitation, with similar sensitivity to precipitation in both periods. Drought was less sensitive to changes in P1 (median of $R C_{T_{-} \mathrm{P} 1}=-0.14$ ), but relatively more sensitive (over three times) in $\mathrm{P} 2$, a time with dramatic global warming (median of $\left.R C_{T_{-} \mathrm{P} 1}=-0.44\right)$. The sensitivity of drought to wind speed was opposite to that of air temperature (median of $R C_{W s} \mathrm{P} 1=-0.40$, median of $R C_{W s} \mathrm{P} 2=-0.13$ ) in both periods. Drought was three times more sensitive to wind speed than temperature in P1, while opposite results were found in $\mathrm{P} 2$.

\section{References}

AghaKouchak A, Cheng L, Mazdiyasni O et al., 2014. Global warming and changes in risk of concurrent climate extremes: Insights from the 2014 California drought. Geophysical Research Letters, 41(24): 8847-8852.

Allen R G, Pereira L S, Raes D et al., 1998. Crop evapotranspiration: Guidelines for computing crop water requirements. FAO Irrigation and Drainage Paper 56. Food and Agriculture of the United Nations, Rome.

Cai W, Zhang Y, Chen Q et al., 2015. Spatial patterns and temporal variability of drought in Beijing-Tianjin-Hebei metropolitan areas in China. Advances in Meteorology, 1-14.

Chen D, Gao G, Xu C et al., 2005. Comparison of the Thornthwaite method and pan data with the standard Penman-Monteith estimates of reference evapotranspiration in China. Climate Research, 28(2): 123-132.

Dai A, 2013. Increasing drought under global warming in observations and models. Nature Climate Change, 3(1): 52-58.

Diffenbaugh N S, Swain D L, Touma D, 2015. Anthropogenic warming has increased drought risk in California. Proceedings of the National Academy of Sciences, 112(13): 3931-3936.

Donat M G, Lowry A L, Alexander L V et al., 2016. More extreme precipitation in the world's dry and wet regions. Nature Climate Change, 6(5): 508-513.

Greve P, Orlowsky B, Mueller B et al., 2014. Global assessment of trends in wetting and drying over land. Nature Geoscience, 7(10): 716-721.

Griffin D, Anchukaitis K J, 2014. How unusual is the 2012-2014 California drought? Geophysical Research Letters, 41(24): 9017-9023.

He J, Yang X, Li J et al., 2015. Spatiotemporal variation of meteorological droughts based on the daily comprehensive drought index in the Haihe River Basin, China. Natural Hazards, 75(2): 199-217.

Huang S, Li P, Huang Q et al., 2017. The propagation from meteorological to hydrological drought and its potential influence factors. Journal of Hydrology, 547: 184-195.

Jones H, Westra R, Sharma A, 2010. Observed relationships between extreme sub-daily precipitation, surface temperature, and relative humidity. Geophysical Research Letters, 37(22). doi: 10.1029/2010GL045081.

Karnieli A, Agam N, Pinker R et al., 2010. Use of NDVI and land surface temperature for drought assessment: Merits and limitations. Journal of Climate, 23(3): 618-633.

Kendall M G, 1975. Rank Correlation Methods. London: Charles Griffin. 
Li Z, Chen Y, Yang J et al., 2014. Potential evapotranspiration and its attribution over the past 50 years in the arid region of Northwest China. Hydrological Processes, 28(3): 1025-1031.

Liu C, Xia J, 2004. Water problems and hydrological research in the Yellow River and the Huai and Hai river basins of China. Hydrological Processes, 18(12): 2197-2210.

Mann H B, 1945. Non-parametric test against trend. Econometrika, 13: 245-259.

Mishra A K, Singh V P, 2010. A review of drought concepts. Journal of Hydrology, 391(1): 202-216.

Perry M A, Niemann J D, 2008. Generation of soil moisture patterns at the catchment scale by EOF interpolation. Hydrology and Earth System Sciences Discussions, 12(1): 39-53.

Qin Y, Yang D, Lei H et al., 2015. Comparative analysis of drought based on precipitation and soil moisture indices in Haihe basin of North China during the period of 1960-2010. Journal of Hydrology, 526: 55-67.

Rajah K, O'Leary T, Turner A et al., 2014. Changes to the temporal distribution of daily precipitation. Geophysical Research Letters, 41(24): 8887-8894.

Santos J F, Pulido-Calvo I, Portela M M, 2010. Spatial and temporal variability of droughts in Portugal. Water Resources Research, 46(3): 742-750.

Schwalm C R, Anderegg W R, Michalak A M et al., 2017. Global patterns of drought recovery. Nature, 548(7666): 202-205.

Sheffield J, Wood E F, Roderick M L, 2012. Little change in global drought over the past 60 years. Nature, 491(7424): 435-438.

Sun F, Roderick M L, Farquhar G D et al., 2010. Partitioning the variance between space and time. Geophysical Research Letters, 37(12). doi: 10.1029/2010GL043323.

Sun F, Roderick M L, Farquhar G D, 2012. Changes in the variability of global land precipitation. Geophysical Research Letters, 39(19). doi: 10.1029/2012GL053369.

Sun H, Wang Y, Chen J et al., 2017. Exposure of population to droughts in the Haihe River Basin under global warming of 1.5 and $2.0^{\circ} \mathrm{C}$ scenarios. Quaternary International, 453: 74-84.

Thornthwaite C W, 1948. An approach toward a rational classification of climate. Geographical Review, 38(1): 55-94.

Wang H, Chen Y, Pan Y et al., 2015. Spatial and temporal variability of drought in the arid region of China and its relationships to teleconnection indices. Journal of hydrology, 523: 283-296.

Wang H, He S, 2015. The north China/northeastern Asia severe summer drought in 2014. Journal of Climate, 28(17): 6667-6681.

Wild M, Gilgen H, Roesch A et al., 2005. From dimming to brightening: Decadal changes in solar radiation at Earth's surface. Science, 308(5723): 847-850.

$\mathrm{Wu} \mathrm{Z}, \mathrm{Xu} \mathrm{H}$, Li Y et al., 2018. Climate and drought risk regionalisation in China based on probabilistic aridity and drought index. Science of The Total Environment, 612: 513-521.

Yang Q, Li M, Zheng Z et al., 2017. Regional applicability of seven meteorological drought indices in China. Science China Earth Sciences, 60(4): 745-760.

Yang Y, McVicar T R, Donohue R J et al., 2017. Lags in hydrologic recovery following an extreme drought: Assessing the roles of climate and catchment characteristics. Water Resources Research, 53: 4821-4837.

Young I R, Zieger S, Babanin A V, 2011. Global trends in wind speed and wave height. Science, 332(6028): $451-455$.

Yu M, Li Q, Hayes M J et al., 2014. Are droughts becoming more frequent or severe in China based on the standardized precipitation evapotranspiration index: 1951-2010? International Journal of Climatology, 34(3): $545-558$.

Zhai J, Huang J, Su B et al., 2017. Intensity-area-duration analysis of droughts in China 1960-2013. Climate Dynamics, 48(1/2): 151-168.

Zhang J, Sun F, Xu J et al., 2016. Dependence of trends in and sensitivity of drought over China (1961-2013) on potential evaporation model. Geophysical Research Letters, 43(1): 206-213.

Zhang L, Wu P, Zhou T, 2017. Aerosol forcing of extreme summer drought over North China. Environmental Research Letters, 12(3). doi: 10.1088/1748-9326/aa5fb3.

Zhang M, He J, Wang B et al., 2013. Extreme drought changes in Southwest China from 1960 to 2009. Journal of Geographical Sciences, 23(1): 3-16. 